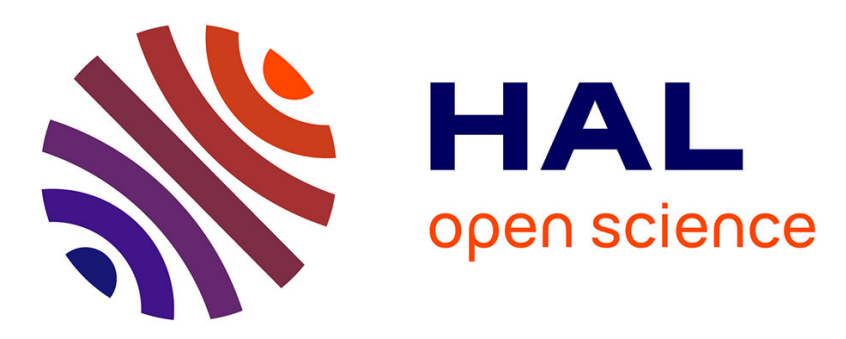

\title{
Fatigue lifetime and tearing resistance of AA2198 Al-Cu-Li alloy friction stir welds: fffect of defects
}

Thomas Le Jolu, Thilo F. Morgeneyer, Anne Denquin, Anne-Françoise

Gourgues-Lorenzon

\section{- To cite this version:}

Thomas Le Jolu, Thilo F. Morgeneyer, Anne Denquin, Anne-Françoise Gourgues-Lorenzon. Fatigue lifetime and tearing resistance of AA2198 Al-Cu-Li alloy friction stir welds: fffect of defects. International Journal of Fatigue, 2015, 70, pp.463-472. 10.1016/j.ijfatigue.2014.07.001 . hal-01102466

\section{HAL Id: hal-01102466 \\ https://hal-mines-paristech.archives-ouvertes.fr/hal-01102466}

Submitted on 12 Jan 2015

HAL is a multi-disciplinary open access archive for the deposit and dissemination of scientific research documents, whether they are published or not. The documents may come from teaching and research institutions in France or abroad, or from public or private research centers.
L'archive ouverte pluridisciplinaire $\mathbf{H A L}$, est destinée au dépôt et à la diffusion de documents scientifiques de niveau recherche, publiés ou non, émanant des établissements d'enseignement et de recherche français ou étrangers, des laboratoires publics ou privés. 
T. Le Jolu et al., International journal of fatigue, 70 (2015) 463-472

\title{
Fatigue lifetime and tearing resistance of AA2198 Al-Cu-Li alloy Friction Stir Welds: Effect of defects
}

\author{
T. Le Jolu ${ }^{\mathrm{a}}$, T. F. Morgeneyer ${ }^{\mathrm{a}, *}$, A. Denquin ${ }^{\mathrm{b}}$, A.F. Gourgues-Lorenzon ${ }^{\mathrm{a}}$ \\ ${ }^{a}$ MINES ParisTech, Centre des Matériaux, CNRS UMR 7633, BP 87, 91003 Evry \\ Cedex, France \\ ${ }^{b}$ ONERA, BP72, 29 avenue de la Division Leclerc, 92322 Chatillon Cedex, France
}

\begin{abstract}
The fatigue strength and failure mechanisms of defect-free ("sound") and flaw bearing friction stir butt-welds of 3.1 mm-thick AA2198-T8 Al-Li-Cu alloy have been investigated via $\mathrm{S}-\mathrm{N}$ curves at $\mathrm{R}=0.1$ using cross weld specimens. The fatigue strength of sound welds is only reduced by $10-15 \%$ at the aimed lifetime of $10^{5}$ cycles compared to the base material. Joint Line Remnant (JLR) bearing welds have a similar fatigue strength as sound welds and the JLR is not the crack initiation site. Kissing Bond (KB) bearing welds that have undergone a weld root polishing show a reduction in fatigue strength by $17 \%$ compared to sound welds. For specimens loaded at or above yield strength of the weld nugget the crack systematically initiates from the KB during the first cycle, which is interpreted further using fracture mechanics. The strongest reduction, about $28 \%$ in fatigue strength, is found for welds with an initial gap between the parent sheets (GAP welds) along with initiation at intergranular surface microcracks. Kahn tear tests show a reduction in tearing resistance for the flaw bearing welds with a similar ranking as for the fatigue strength.
\end{abstract}

Keywords: fatigue, S-N curves, friction stir welding, defects, $2198 \mathrm{Al}-\mathrm{Cu}-\mathrm{Li}$ alloy, ductile tearing

\footnotetext{
${ }^{*}$ Corresponding author, thilo.morgeneyer@ensmp.fr
}

doi:10.1016/j.ijfatigue.2014.07.001 
T. Le Jolu et al., International journal of fatigue, 70 (2015) 463-472

\section{Introduction}

Demand for reduction in fuel consumption and cost in the aerospace industry stimulates research for new materials and joining processes. Friction stir welding (FSW) offers the advantages of avoiding hot cracking and limiting component distortion. The advantages of using this process are mainly the possibilities to weld alloys traditionally considered as unweldable, the absence of defects such as porosities or cracks and the low distortion and residual stresses as melting and solidification are avoided. Application of this process to aluminium alloys has been extensively reviewed recently by [1]. The latest generation of Al-Cu-Li alloys (such as AA2198) is considered as candidate alloys for future aerospace applications thanks to their beneficial density to strength ratio, enhanced mechanical properties and corrosion resistance compared to other damage tolerant alloys allowing for weight savings $[2 ; 3 ; 4 ; 5]$. Mechanical properties such as strength, fatigue properties and tearing resistance of FSW joints of AA2198 Al-alloys are therefore of interest $[4 ; 6 ; 7 ; 8 ; 9 ; 10]$. For certain FSW processing conditions, internal flaws and defects may appear that can affect fatigue properties of the welds. The natural oxide layer present on butt surfaces before welding may lead to a discontinuous, wavy surface after welding. The nomenclature of this feature is not established and unified in the literature and it has been referred to as Joint Line Remnant (JLR), lazy S, zigzag curve or zigzag line $[11 ; 12 ; 13 ; 14 ; 8 ; 15]$. It will be referred to as JLR hereafter. The JLR may be connected for some particular welding conditions to the weld root and induce fracture during severe bending of the weld. In this particular case, it is referred to as Kissing Bond (KB), weak bond or root flaw $[16 ; 17 ; 18 ; 19 ; 20 ; 21]$. It will be referred to as KB hereafter. KBs seems to originate from insufficient mixing of matter close to the initial butt surfaces $[22 ; 18 ; 19 ; 13 ; 23]$ - The effect of these features on the fatigue lifetime has been the subject of several studies $[16 ; 19 ; 24 ; 20 ; 14]$. However, in most cases data on flaw bearing welds is only compared to literature values obtained for experimental conditions that are generally different from one study to another. Some authors found fatigue crack initiation from weld defects $[16 ; 19 ; 24 ; 20]$ and a fatigue life reduction by up to $50 \%$ [20] but others did not find any effect [14]. Another kind of feature may appear if there is some distance (a gap) left between the two sheets to be butt welded. Metallographic observations of cross-sections showed that leaving a gap during welding may cause the presence of cavities. In [25] it was found that so-called "wormholes" may ap- 
T. Le Jolu et al., International journal of fatigue, 70 (2015) 463-472

pear in the weld when an initial gap wider than $0.5 \mathrm{~mm}$ is left. Some defects can be remediated by increasing the heat input energy [17;26]. Little data is available about the consequences of such a gap on the mechanical properties of the welded joint, and in particular its fatigue strength.

The aim of the present study is to investigate the effect of JLR, KB and gap-induced defects on the fatigue behavior of FSW joints of an Al-Cu-Li alloy for aerospace applications. S-N (or Wöhler) curves are compared to those of the base material and of sound welds (welded by having the the FSW tool travel inside one sheet). For the first time a rigourous study comparing the flaw bearing welds to sound welds, all made from the same material and tested in the same experimental conditions, is made. Detailed fractography is carried out to link fatigue crack initiation sites and propagation paths to the presence of defects and to previous results on monotonic loading [9]. The number of cycles needed for fatigue crack initiation are studied via interrupted fatigue tests and subsequently interpreted in terms of fracture mechanics and fatigue crack propagation thresholds. Finally, Kahn tear tests using specimens with notches placed in the weld centre are carried out to estimate the tearing resistance of the flaw bearing welds and thus the residual strength of cross-weld specimens already loaded in fatigue.

\section{Experimental}

Material:: A 3.1-mm-thick sheet of AA2198-T851 was used in this study. Its chemical composition is: $\mathrm{Al}$ balance $-3.20 \mathrm{Cu}-0.98 \mathrm{Li}-0.31 \mathrm{Ag}-0.31$ $\mathrm{Mg}-0.11 \mathrm{Zr}-0.04 \mathrm{Fe}-0.03 \mathrm{Si}$ (wt \%) and aged at $155^{\circ} \mathrm{C}$ for $16 \mathrm{~h}$. Pancakeshaped grains (thickness 15-20 $\mu \mathrm{m}$ ) were observed throughout the thickness, except at the skin of the sheet, which was composed of coarser pancake grains (100 $\mu \mathrm{m}$ in thickness) over a depth of $0.5 \mathrm{~mm}$ at each side. In the following, $\mathrm{L}$ denotes the rolling direction of the sheet, $\mathrm{T}$ its long transverse direction and $\mathrm{S}$ its short transverse direction. In the $(\mathrm{T}, \mathrm{S})$ plane, the Vickers hardness, under a load of $0.981 \mathrm{~N}$, was $150 \mathrm{HV}_{0.1}$, except at mid-thickness $\left(137 \mathrm{HV}_{0.1}\right.$. [9].

Welding: FSW joints parallel to the rolling direction $\mathrm{L}$ were made at ONERA from $500 \mathrm{~mm}$ (L) x $150 \mathrm{~mm}$ (T) coupons with optimised welding parameters to avoid external defects such as flashes or grooves. Except otherwise stated, the welding machine was displacement-controlled with a travelling speed of $480 \mathrm{~mm} \cdot \mathrm{min}^{-1}$, a rotational speed of $1200 \mathrm{rpm}$, a retractable threaded tool, with $13 \mathrm{~mm}$ in shoulder diameter and $4.2 \mathrm{~mm}$ in pin diameter. 
T. Le Jolu et al., International journal of fatigue, 70 (2015) 463-472

The first $100 \mathrm{~mm}$ (extended to $150 \mathrm{~mm}$ when necessary) of the weld was discarded from analysis to ensure that specimens were cut from a region where axial force (or axial displacement if displacement-controlled) was stable (between 4 and $5 \mathrm{kN}$ for the load-controlled conditions). Four kinds of welds were fabricated from the same sheet and investigated in the as-welded condition (see Figure 1): So-called "sound welds" were made by moving the tool inside a single sheet i.e. by a stir-in-plate process. This ensures the absence of native oxide at blank edges just before welding. JLR-bearing welds resulted from natural oxidation of the welded coupons. KB-bearing welds were made as for JLR but with retracting the pin by $80 \mu \mathrm{m}$ to change mixing conditions within the weld. The existence of the KB was checked by fracturing samples under severe bending. GAP welds were fabricated with a constant clearance of either $0.3 \mathrm{~mm}$ (GAP $0.3 \mathrm{~mm}$ : $10 \%$ of the parent sheet thickness) or $0.7 \mathrm{~mm}$ (GAP $0.7 \mathrm{~mm}: 23 \%$ of the parent sheet thickness). These welds were realised under constant load $(4 \mathrm{kN})$ and a stable pin displacement after about 150 $\mathrm{mm}$.

Surface preparation: Before testing, specimens were ground at the corners and on the upper surface to limit stress concentrations with 600 and 1200-grit SiC papers, parallel to the loading direction to avoid fatigue crack initiation from surface tool rotation marks. To take the location of the most tilted part of the KB (Figure 2) and of features induced by GAP-welding [9] into account, the weld root surface was ground neither for the as-welded root $\mathrm{KB}$ welds nor for the GAP welds. In Figure 2 the ground part of the KB typically removed by grinding is indicated by a dashed line.

Mechanical testing: Fatigue specimens for S-N (Wöhler) fatigue curves were tested along T (i.e. cross-weld) direction. A sinusoidal load versus time function was used, applying a stress ratio, $\mathrm{R}$, of 0.1 and using a frequency of $20 \mathrm{~Hz}$. Fatigue specimen geometries for the base material and for the welded material are shown in Figure 3, according to ASTM E466-07 testing standard. The cross weld specimens had tangentially blending fillets, so that all regions of the welded joint were exposed to the same engineering stress level. Kahn tear tests have been carried out in accordance with standard ASTM B 871-01; 2001. The crack mouth opening displacement was recorded using a clip gauge.

Fractography and metallography: fracture surfaces were examined using a LEO $1450 \mathrm{VP}$ scanning electron microscope (SEM). To reveal the grain structure metallographic samples were carefully cross-sectioned very close to the fatigue crack initiation site, polished with diamond pastes and 

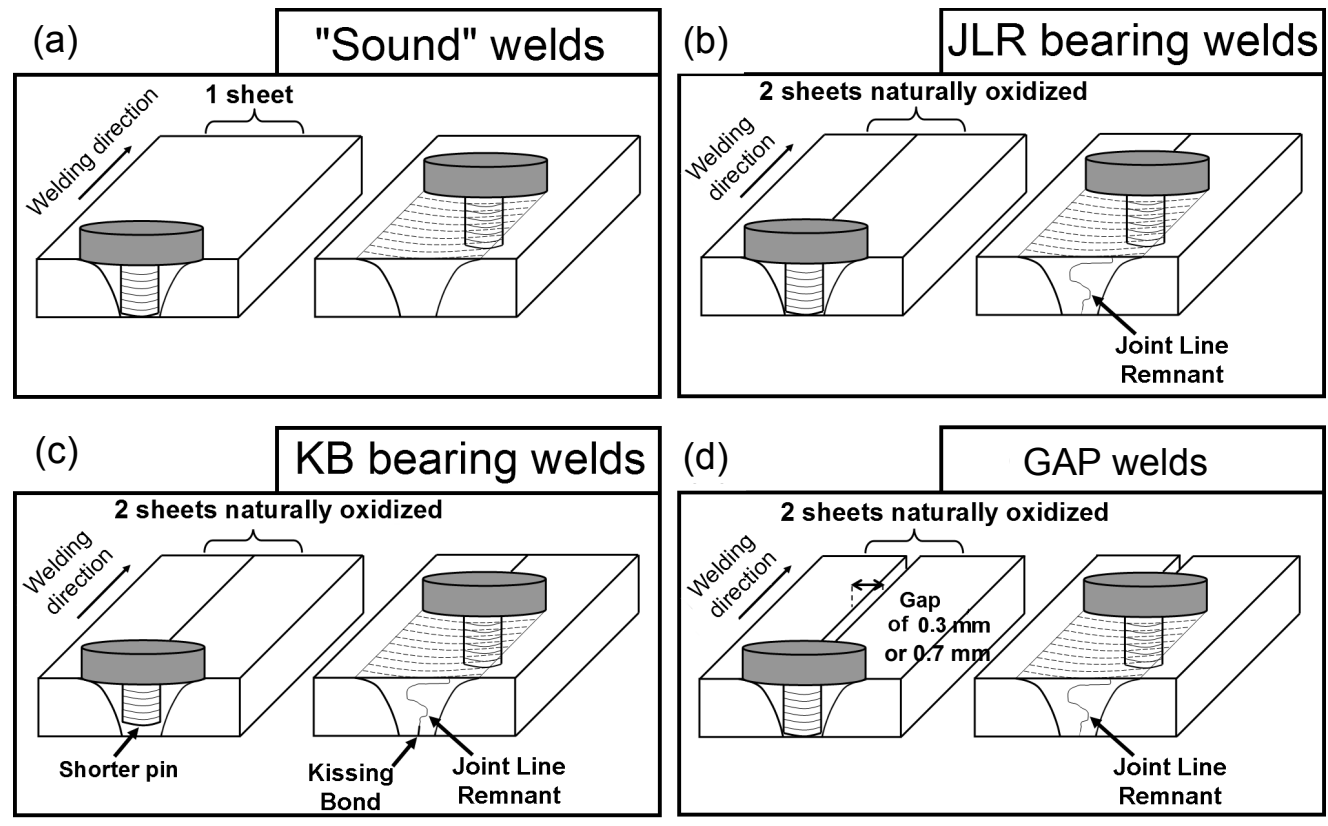

Figure 1: Schematic drawing of (a) sound, (b) JLR bearing, (c) KB bearing welds and (d) welds with a gap left between the parent sheets (after [9])

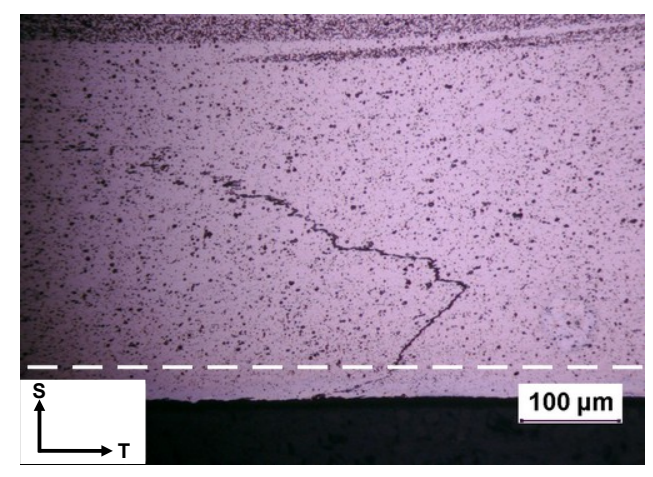

Figure 2: Optical micrograph of a KB bearing weld, the dotted line indicates the part of the KB that is removed by grinding of the surface treated specimens 


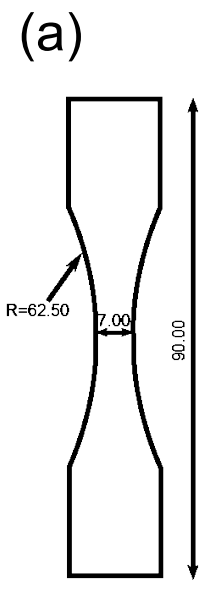

(b)

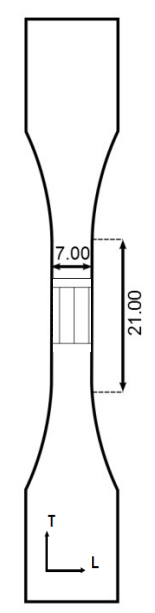

(c)

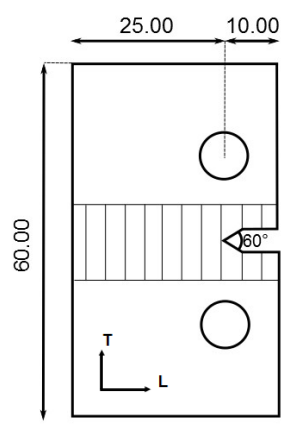

Figure 3: Specimen geometries (all dimensions in $\mathrm{mm}$ ): a) base material $\mathrm{S}-\mathrm{N}$ fatigue specimen b) FSW cross weld S-N fatigue specimen c) Kahn tear test specimen, the hatched region schematically represents the upper surface of the weld

first etched by anodic oxidation (3\% aqueous solution of tetrafluoroboric acid in water, under $30 \mathrm{~V}$ with respect to a pure aluminium electrode, for 2 - 3 min) before observation under polarised light optical microscopy (LOM). For defect observation, the same regions were subsequently chemically etched with the Dix-Keller reagent $\left(2 \mathrm{~mL} \mathrm{HF}, 3 \mathrm{~mL} \mathrm{HCl}, 20 \mathrm{~mL} \mathrm{HNO}_{3}\right.$, and 175 $\mathrm{mL}$ distilled water) before a second LOM observation under white light.

\section{Fatigue Results and Discussion}

The aimed lifetime for the targeted FSW welded structural parts is $10^{5}$ cycles. The load levels corresponding to this lifetime are found to be above yield strength of the weld nugget (WN), the thermomechanically affected zones (TMAZs) and heat affected zones (HAZs) [8; 9]. As a consequence, the entire weld deforms plastically and any residual stresses may be assumed to be redistributed during the first load cycle [27]. This implies that findings for the weld defect behavior during monotonic loading may also be relevant for the fatigue behavior. 
T. Le Jolu et al., International journal of fatigue, 70 (2015) 463-472

\subsection{Fatigue of base material, sound and JLR-bearing welds}

Figure 5 shows the results in terms of S-N curves for the base material, sound welds and welds containg a JLR.

Compared to the base material, the fatigue strength for the aimed lifetime of $10^{5}$ cycles is reduced by about $10 \%$ for sound welds and by $15 \%$ for the welds containing a JLR. This means that the effect of JLR on the fatigue lifetime seems very limited with respect to the experimental scatter in fatigue strength (see also [8]). Sound welds have a good fatigue resistance compared to the base material as the weld hardens during its plastic deformation of the first load cycle, which is consistent with the results for monotonic loading [9]. Above $10^{6}$ cycles the differences between the base material and the welds are more pronounced. The decrease in fatigue strength is $20-25 \%$ with respect to the base material. However, the difference in fatigue lifetime between sound welds and welds containing a JLR is again very limited (about 7\%). Amongst the specimens for which crack initiation has taken place in the weld nugget (WN) none of the cracks initiatied from the JLR. In other words, the similarity in fatigue life for sound and the JLR bearing welds is consistent with the fact that JLR does not affect fatigue crack initiation or propagation mechanisms. The cohesion of the JLR seems too strong to be opened during loading. Apparently the oxide particles are sufficiently small and do not act as stress concentrators in the way that they could initiate a crack in this location.

\subsection{Fatigue of $K B$ bearing welds}

Figure 4 shows the S-N curves for welds containing a Kissing Bond and for GAP-welds compared to the results for sound and JLR-welds. The horizontal line in this graph indicates conditionsfor which the maximum stress reaches the yield stress of the WN. For loading above these levels stresses are found to be mainly relieved when macroscopic plastic deformation of the weld is perfomed [27]. Indeed, it has been identified in the literature that residual stresses are generated during the FSW process for joining of similar alloy types as the one studied here. They may greatly influence the fatigue properties and growth rates of the different weld zones: Residual stresses along the welding direction ranging from -40 to $60 \mathrm{MPa}$ [27], -50 to $200 \mathrm{MPa}$ [28], -50 to $120 \mathrm{MPa}$ [29], -90 to $130 \mathrm{MPa}$ [30] have been measured. The magnitude of these stresses decrease with decreasing specimen size [29]. In the direction perpendicular to the weld direction residual stresses are found to be lower than along the welding direction ranging from -25 to $25 \mathrm{MPa}$ 
[28], -10 to $50 \mathrm{MPa}$ [29]. These levels of residual stresses may also be present in our case for loading at stress levels below yield stress of the WN.

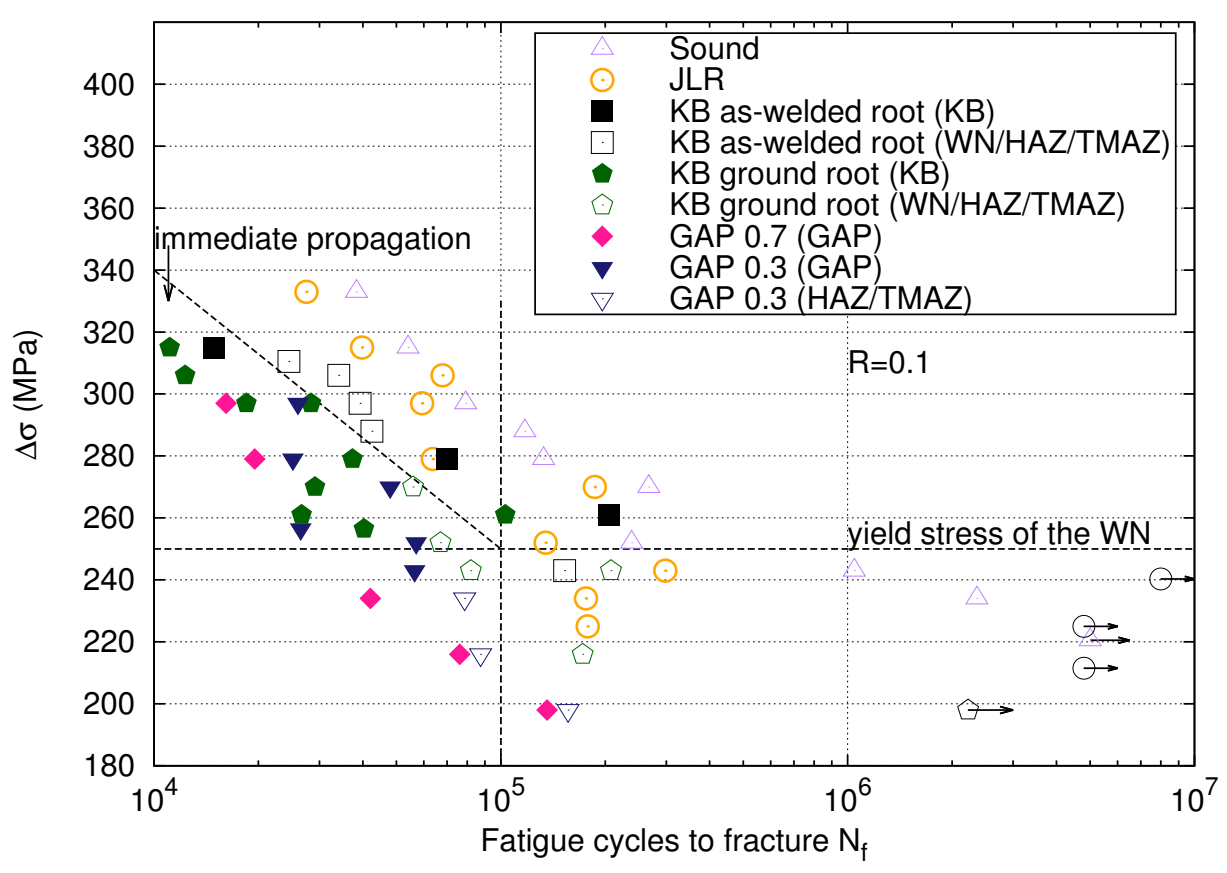

Figure 4: S-N curves for sound and defect-bearing welds; right hand arrows denote the abscence of failure; the crack initiation sites are indicated between brackets

\subsubsection{Kissing Bond bearing specimens with ground weld root}

The reduction in fatigue lifetime at $10^{5}$ cycles for the KB-bearing welds after weld root surface treatment is $20 \%$ with respect to sound welds. The reduction in fatigue lifetime in the regime below $10^{5}$ cycles is higher than for the regime above $10^{5}$ cycles, in which the fatigue strength is lower but still similar to that of welds containg a JLR.

Fractographic and metallographic examination of the different specimens showed that the fatigue crack initiation site is a function of the applied stress range (Figure 4). For maximum stresses above a critical value (about 260 $\mathrm{MPa}$, which is close to the yield stress of the weld nugget, see [9]) the fatigue crack initiation site is the opened kissing bond. This suggests that during the first loading cycle the KB is opened at yielding of the weld nugget as already shown in a monotonic SEM in situ test [9]. This opened KB seems to act 


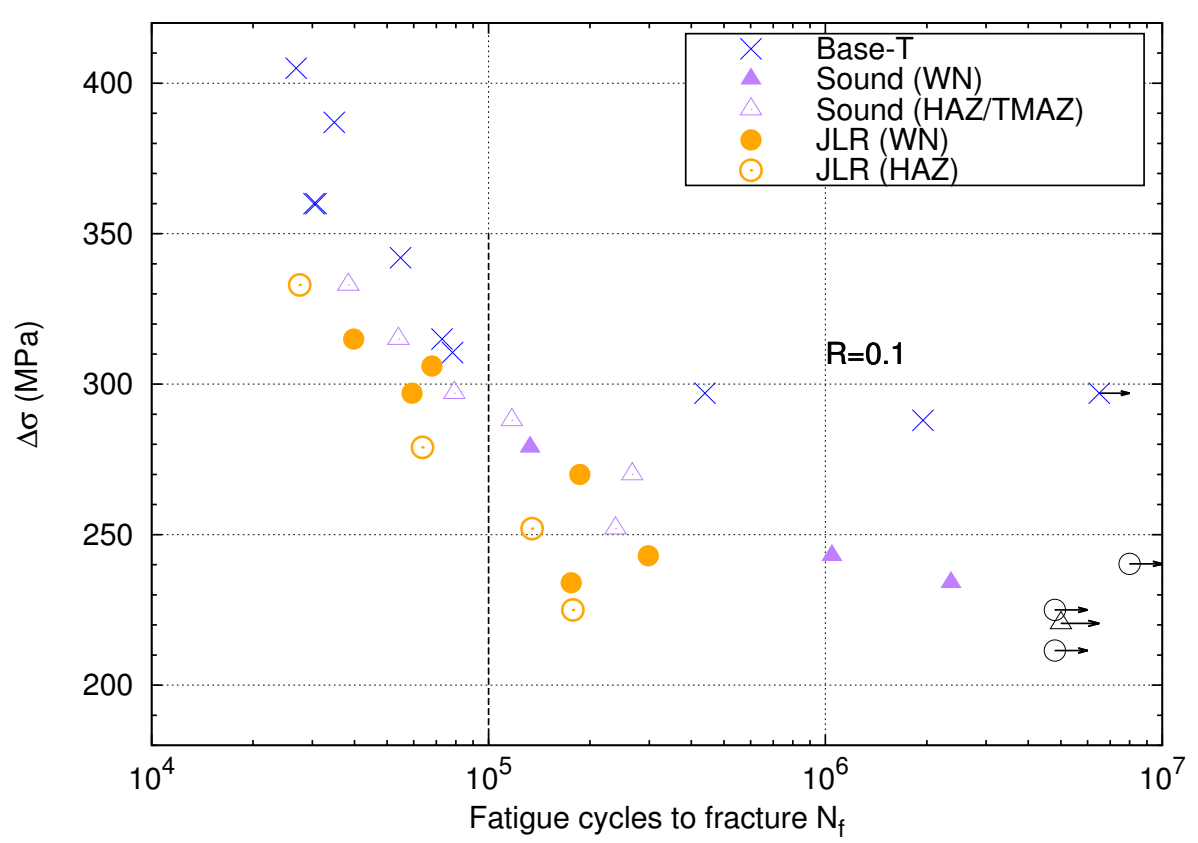

Figure 5: S-N curves for base material, sound welds and welds containing a joint line remnant; the failure initiation sites determined by fractography and cross-sectional observations are indicated in brackets; tests interrupted failure are indicated by arrows

as an initial crack during the following fatigue cycles (Figure 6) and reduces the number of cycles for fatigue crack initiation down to only one cycle. Figure 6b) shows the KB fracture surface followed by the fatigue crack with a typical morphology for fatigue of the $\mathrm{WN}$ material [8]. Figure 6c) shows a zoom on the KB fracture zone where no fatigue striation are seen.

In order to confirm this scenario two additional fatigue tests have been carried out for a stress range $(\Delta \sigma=280 \mathrm{MPa})$ involving plastic yield of the weld nugget. They were interrupted after respectively 7,000 and 15,000 cycles, which corresponds respectively to $20 \%$ and $40 \%$ of the expected lifetime. After cycling, monotonic tensile loading was applied to fully fracture the specimen. The optical cross section of the specimen as well as its fracture surface are shown in Figure 7 for the specimen that has undergone 15,000 cycles. From cross-section observation it becomes clear that the crack initially followed the KB line. In accordance with Figure 6, the opened KB can be identified on the fracture surface as a rough and striated region (Figure $7 \mathrm{c}, \mathrm{d}$ ) [20] followed by a fatigue crack propagation region similar to that observed 

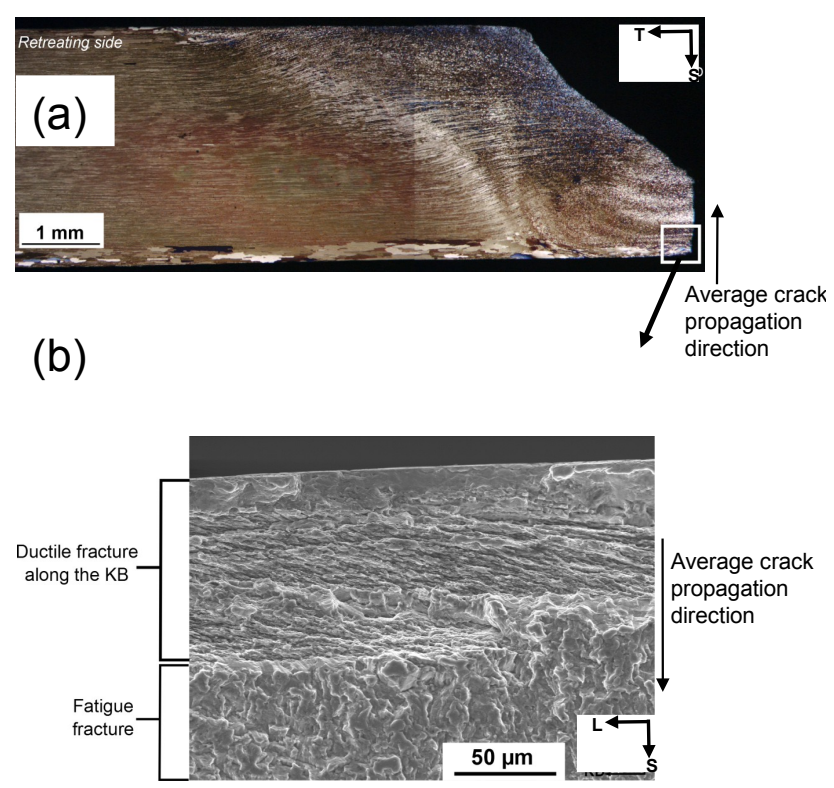

(c)

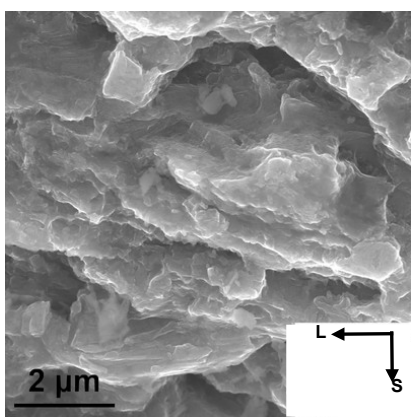

Figure 6: KB welds after failure (a) LOM micrograph of a cross-section perpendicular to the fatigue crack in vicinity of the initiation site (b) SEM fractograph of the initiation site showing the KB part (opened during the first cycle) and the subsequent fatigue propagation region. (c) closer view of the $\mathrm{KB}$ fracture surface

for specimens broken in fatigue, and the final fracture region caused by subsequent monotonic loading. The fatigue crack initiates and propagates from the entire crack front formed by the opened KB. This implies that in every location along this front the mechanical and microstructural conditions to immediately initiate and propagate a fatigue crack are met. This is consistent with the result for monotonic loading in [9] where KB opening was found to occur for an applied stress of at least $260 \mathrm{MPa}$. These tests confirm that the number of cycles for fatigue crack initiation may vanish due to the $\mathrm{KB}$ 
defect opening acting as an initial crack/notch if blunt.

(a)

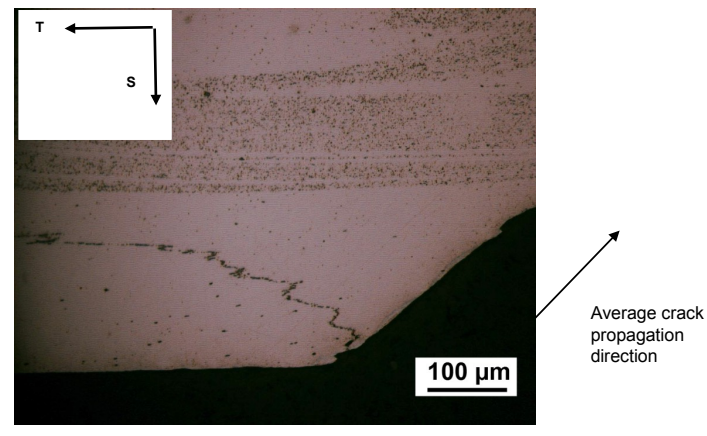

(b)

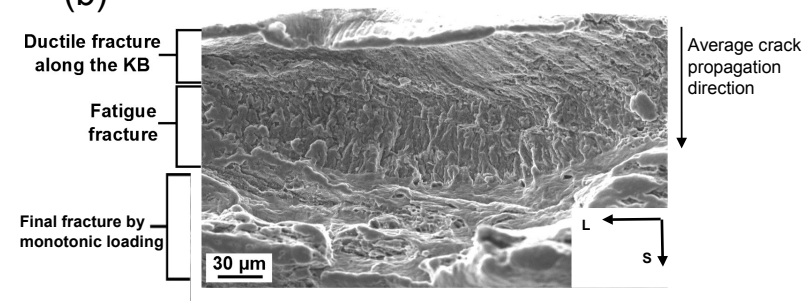

Figure 7: KB bearing fatigue specimen tested in fatigue $(\Delta \sigma=280 \mathrm{MPa})$ for 15,000 cycles then fractured by monotonic tension: (a) optical micrograph of a cross section containing the crack initiation region (b) fractography of the crack initiation zone

\subsubsection{Welds containing a Kissing Bond with as-received weld root surface}

From Figure 4 it can be seen that the fatigue lifetime of welds containing KB but as-received weld root surface is not significantly lower than for sound welds and paradoxically higher than for welds that have undergone a weld root surface treatment resulting in reduced surface roughness. The fatigue crack initiation site assessment for different stress ranges reveals that there is no clear difference in crack initiation site. When investigating the fracture surfaces of the few specimens for which fatigue crack initiation has started from the opened KB it can be seen that the opening depth is substantially lower than for the surface treated specimens, compare with Figure 8c). This also highlights that the orientation of the KB with respect to the loading direction plays a role for ductile opening of the KB: The absence of surface 
treatment leaves at the very specimen surface a KB locally tilted by only 20 degrees with respect to the loading direction (also see Figure 2). The normal stress applied to this part of the KB during uniaxial tension of the specimen is therefore lower than for the KB part that was brought closer to the surface for the surface treated specimens. Thus, the orientation of the KB defect with respect to the loading direction of the very surface of the fatigue specimen seems of utmost importance in the fatigue lifetime of KB bearing welds. This difference in orientation seems to cause the different crack initiation mechanisms and explains the surprising effect of surface condition on the fatigue lifetime of these welds. For the specimens without surface treatment the KB is thus either not open or it is open below the free surface but not leading to fatigue crack propagation and, as a consequence, to the fatal crack.

(a)

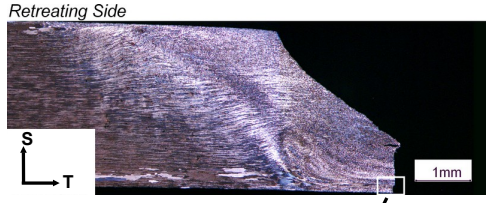

(b)
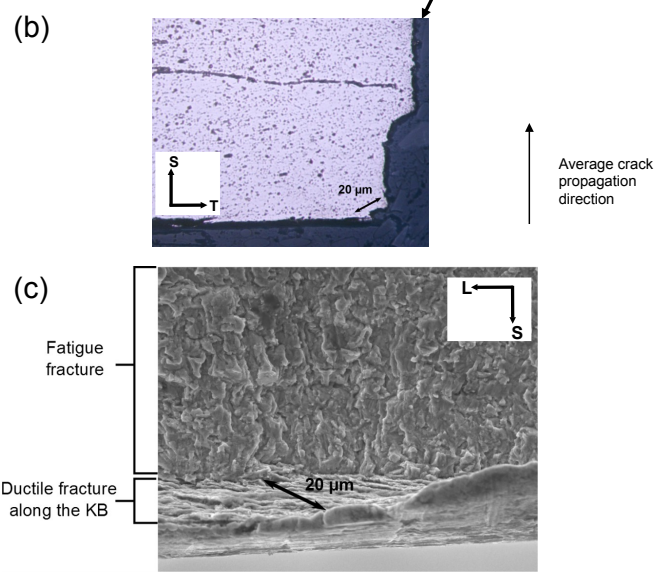

Figure 8: Fractured KB welds with as-received weld root surface (a) LOM of a cross section through the fatigue zone close to the initiation site (The fatigue zone is normal to the loading direction) (b) zoom on the fatigue initiation zone following the KB (c) SEM fractography of the initiation site showing the KB part opened during the first load cycle and the subsequent fatigue propagation region. 
T. Le Jolu et al., International journal of fatigue, 70 (2015) 463-472

\subsubsection{Interpretation of the results for welds containing $K B$ in terms of frac- ture mechanics}

For the surface-traeted specimen the open KB plays the role of an initial crack/notch after the first quarter of the first load cycle. The real stress/strain state around this crack may be complex: During opening of the KB during the first load cycle, a comparatively large plastic zone may be created that involves residual stresses that may impact the fatigue crack behavior. When the crack starts from the open KB it is a short fatigue crack, that is expected to be hardly prone to crack closure effects at the beginning of fatigue crack progression despite the load ratio of $R=0.1$. This may change during crack progression. Some of these complex effects are not considered here as it has been shown here that a fatigue crack was already growing at $20 \%$ of the total lifetime. There are little literature data on effective threshold values for alloy 2198 [6] and no data for FSW welds of this material. Simple concepts of fracture mechanics are used to try to capture mechanical first order effects.

The stress intensity factor range is given by:

$$
\Delta K=\Delta \sigma_{n o m} \cdot \sqrt{\pi a} \cdot f\left(\frac{a}{w}\right)
$$

where $\sigma_{n o m}$ is the applied far-field stress, $a$ is the crack length (the maximum depth of the open KB in our case being considered to be conservative), $w$ is the ligament width, i.e. approximately the sample thickness $(3.1 \mathrm{~mm}$ here) and $f\left(\frac{a}{w}\right)$ is a correction factor depending on the geometry of the considered specimen. The correction factor chosen here is for an infinitely wide sheet with a crack (here, the open KB) on the surface as in [31], which applies if $\left(\frac{a}{w}<<1\right)$. Here, the specimen width is substantially larger than the thickness and the length of the straight crack is substantially smaller than the specimen thickness so that:

$$
f\left(\frac{a}{w}\right)=1.12-0.231\left(\frac{a}{w}\right)+10.55\left(\frac{a}{w}\right)^{2}-21.72\left(\frac{a}{w}\right)^{3}+30.39\left(\frac{a}{w}\right)^{4}
$$

In Figure 9a the KB opening depth is plotted as a function of the number of cycles to fracture. The scatter bars around each measurement point are given as an estimate of the variability of $\mathrm{KB}$ opening depth on the fracture surface for each specimen. Some trends for a decrease in lifetime with an increase in initial KB opening depth may be suspected but the applied stress range is not accounted for in this graph. In Figure $9 \mathrm{~b}$ the stress intensity 
factor range $\Delta K$ right after opening of the $\mathrm{KB}$ calculated using equations 1 and 2 is plotted as a function of the number of cycles to fracture. $a$ is the max. $\mathrm{KB}$ crack length measured on fracture surfaces and $\Delta \sigma$ the applied stress range. From the vast majority of points in Figure 9b, it becomes evident that the number of cycles to fracture is clearly a function of the stress intensity factor range, which is consistent with the fact that the fatigue crack starts from the first load cycle onwards and that the fatigue crack propagation rate increases with increasing stress intensity factor range without crack closure effects. However, there are three points for a stress intensity factor range $\Delta K=1.0-1.5 \mathrm{MPa} \sqrt{\mathrm{m}}$ that do not follow this trend. The increased lifetime of these specimens might be due to a stress intensity factor range below a critical value $\Delta \mathrm{K}_{\text {threshold }}$, for which the crack initiated from the open $\mathrm{KB}$ would not propagate immediately. When comparing these values of $\Delta \mathrm{K}_{\text {threshold }}$ with values from the literature for the base material it is found that these values correspond to threshold values already reported for the base material in T8 condition [32]. These values have been obtained with fracture mechanics specimens containing long cracks where crack closure is supposed to take place. To account for crack closure $\Delta \mathrm{K}_{\text {eff,threshold have }}$ been calculated in the literature and will be compared to our values for short cracks here.

Indeed, the opened kissing bond may be considered as a physically short crack following the definition by [33]. In this case crack closure phenomena do not occur at crack initiation. The short fatigue crack behavior may thus be assessed further using the arrested fatigue tests of the weld root surface treated kissing bond to calculate average crack propagation rates for the applied cycles (see table 1).

The fatigue crack propagation rates are in average slightly higher for the test interrupted after 7,000 cycles than for the test interrupted after 15,000 cycles. When assuming the same propagation rate during 7,000 cycles for the 15,000-cycle-test and calculating the average rate for the remaining 8,000 cycles it becomes even clearer that the propagation rate reduces with increasing crack length $\left(1.25-3.75 \times 10^{-9} \mathrm{~m} /\right.$ cycle$)$ which is an indication for a short fatigue crack behavior: due to increasing crack length crack closure effects are supposed to become more pronounced. When comparing the average fatigue crack propagation rate ranges with literature data for the base material and also for FSW welds tested at $\mathrm{R}=0.1$ similar values are found $(3$ - $9 \times 10^{-9} \mathrm{~m} /$ cycle) $[34 ; 32 ; 6]$. 
T. Le Jolu et al., International journal of fatigue, 70 (2015) 463-472

Table 1: $\Delta \mathrm{K}$ and average fatigue crack propagation rates calculated from interrupted fatigue tests containing a surface treated kissing bond $(\Delta \sigma=279 \mathrm{MPa})$

\begin{tabular}{|c|c|c|}
\hline & $\begin{array}{c}\mathrm{KB}-2 \\
(7,000 \text { cycles })\end{array}$ & $\begin{array}{c}\text { KB-1 } \\
(15,000 \text { cycles })\end{array}$ \\
\hline ductile crack length $(\mu \mathrm{m})$ & 60 & 60 \\
$\Delta \mathrm{K}(\mathrm{MPa} \sqrt{m})$ at test start & 4.3 & 4.3 \\
\hline local fatigue crack length $(\mu \mathrm{m})$ & $30-50$ & $40-60$ \\
$\Delta \mathrm{K}(\mathrm{MPa} \sqrt{m})$ at test end & $5.2-5.8$ & $5.5-6.1$ \\
\hline average crack propagation rate & $4.3-7.1$ & $2.6-4.0$ \\
$\left(10^{-9} \mathrm{~m} /\right.$ cycle $)$ & & \\
\hline
\end{tabular}
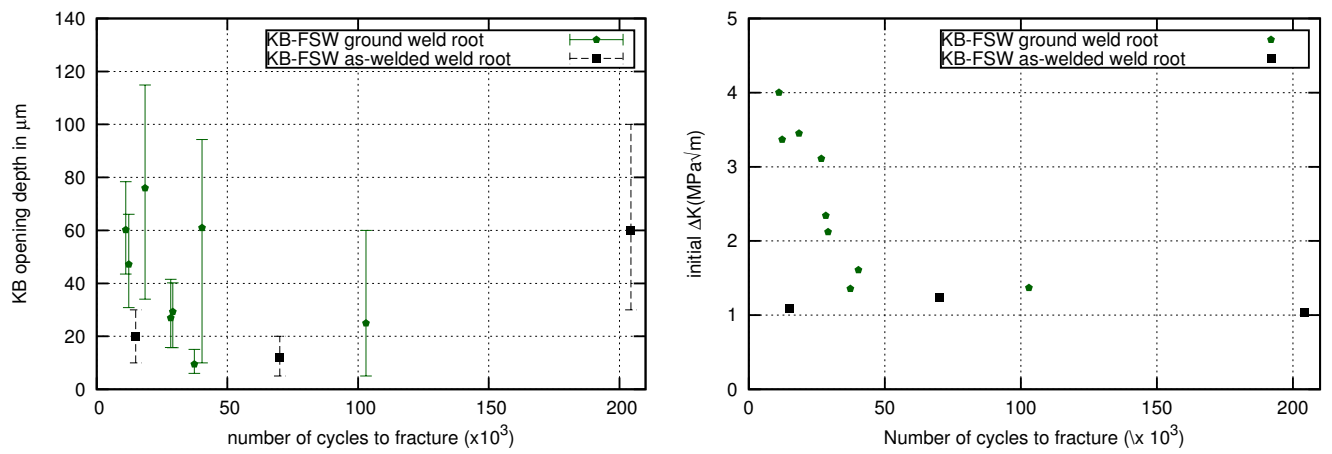

Figure 9: Effect of early opening of the KB on fatigue lifetime a) ductile KB opening depth versus number of cycles to fracture; bars indicate the scatter in length of the initial crack due to opening of the $\mathrm{KB}$; b) initial value of $\Delta \mathrm{K}$ caused by opened $\mathrm{KB}$ versus number of cycles to fracture

\subsection{Fatigue behavior of welds containing a GAP $0.3 \mathrm{~mm}$ defect and of welds} containing a GAP $0.7 \mathrm{~mm}$ defect

In Figure 4 the fatigue test results for the welds with an initial GAP of g.3. mm and $0.7 \mathrm{~mm}$ aregiyen A reduction in fatigue strength for the aimed 
T. Le Jolu et al., International journal of fatigue, 70 (2015) 463-472

lifetime of 100,000 cycles by $25-30 \%$ is found for the GAP $0.3 \mathrm{~mm}$ compared to sound welds. The results for the GAP $0.7 \mathrm{~mm}$ weld are situated in the lower bound of the results for the GAP $0.3 \mathrm{~mm}$ defect. For the GAP 0.3 $\mathrm{mm}$, the crack initiation site is a function of the applied load level as already found for the KB welds. For the GAP $0.7 \mathrm{~mm}$ welds, the fatigue crack always initiated from the defect. In Figure 10 a typical fracture surface for fatigue crack initiation at a GAP defect in the weld nugget can be seen. This fracture surface is intergranular. It could be assumed that during the fracture process a crack initates during the first load cycle, here via intergranular cracking. Intergranular fracture and decoration of the grain boundaries with oxide particles and copper rich particles has been shown in [9]. This defect is the most detrimental one in terms of fatigue resistance. In this study the stress range for which a slope change in the $\mathrm{S}-\mathrm{N}$ curve occurs has even not been found for these welds. The GAP $0.3 \mathrm{~mm}$ defect is difficult to detect as it is not the crack initiation site for monotonic loading (contrary to the KB). Surprisingly, the fatigue lifetimes for those GAP $0.3 \mathrm{~mm}$ welds, that do not fail from the defect, are also substantially lower than those of sound welds. This may partially be due to the fact that the weld root surface has not been treated resulting in a rougher surface than e.g. sound welds. However, due to welding with the GAP and as suggested by the modified resistance to intergranular cracking in GAP $0.7 \mathrm{~mm}$ welds, thermal-mechanical cycles experienced during FSW as well as quality of stirring, even if not leading to cavity formation, might differ from those of sound welds even in the TMAZ and HAZ. This could result in a lower fatigue resistance of these zones. However, the hardness profiles were the same for sound and GAP welds, indicating that the weakening of the GAP defect is likely to be a very local process (e.g. GB weakening).

\section{Ductile Tearing Results and Discussion}

$\mathrm{S}-\mathrm{N}$ curve tests do not readily allow to distiguish between the part in lifetime due to number of cycles to initiation/propagation and the influence of the defects on final fracture during the very last cycle. Indeed, as the welds investigated here contain different kinds of defects their final fracture behavior, i.e. toughness/tearing resistance may be different. A lower toughness would also reduce the number of cycles to fracture as final fracture would occur at a smaller fatigue crack length. To get a first estimate of the tearing resistance of the welds containing different defects, Kahn tear tests 
T. Le Jolu et al., International journal of fatigue, 70 (2015) 463-472

have been carried out here with a notch located in the centre of the weld (Figure 3). The initial notch location was expected to influence the tearing resistance as the different weld zones behave differently in terms of plastic flow [9]. A limitation of this assessment is that the defects are only relevant for final fracture if the fatigue crack systematically initiates and propagates in the $\mathrm{WN}$ and in its vicinity: this is only the case for the KB and GAP welds. Additionally, in these cases the crack propagation direction is normal to the sheet surface and not within the sheet plane as in the present Kahn specimen configuration. However, via this approach the weld defects are exposed to high levels of stress triaxiality which are particularly severe and may represent those in front of fatigue cracks. Figure 11a shows the nominal stress versus crack mouth opening displacement curves for base material along $\mathrm{L}$ and $\mathrm{T}$ directions, sound welds, welds containing a JLR and welds containing a KB. The peak loads between the different specimens are very different. The unit initiation energy (UIE) has been used as a measure of the tearing resistance. It is defined as the area under the load versus pin displacement curve up to maximum load [35] and is related to plane strain fracture toughness [35]. The UIE values are given in table 2. The same trend as for fatigue strength is found for the tearing resistance: the base material is the strongest material followed by sound, JLR bearing and KB bearing welds. For the sound welds, crack deviation took place from the weld nugget into the TMAZ on the retreating side that is known to be the softest zone in these welds [9], see Figure 11b. For the weld containing a JLR the crack stays in the weld nugget (see Figure 11c). On the fracture surface a step can be seen (see Figure 11c) that turned out to be the JLR via cross sectioning. The JLR seems to weaken the weld nugget so that the crack stays in the WN centre and opens the JLR where the classically found slant crack path [36] in high strength Al-alloys crosses the JLR. It would be worth investigating any tunneling effect induced by the presence of the JLR. The UIE of the welds containing a KB is reduced further. On the fracture surface it can be seen that the KB is opened at crack initiation but does not contribute to fracture during crack propagation (Figure 11d). The crack propagation resistance is thus cloase to that of a JLR bearing weld, as KB weldsalso contain a JLR. GAP welds have not been tested here due to a lack of material, but the result would have been relvant to the interpretation of the fatigue results. In summary, it can be seen that the investigated FSW-induced defects may reduce toughness if a notch (or a fatigue crack) is in their vicinity. 
Table 2: Unit initiation energy (UIE) calculated from Kahn tear tests

\begin{tabular}{|c|c|}
\hline & UIE $(\mathrm{N} / \mathrm{m})$ \\
\hline Base: L-T & $181-182$ \\
\hline Base: T-L & $166-171$ \\
\hline Sound weld & $138-139$ \\
\hline JLR & $117-119$ \\
\hline KB & $87-92$ \\
\hline
\end{tabular}

(a)

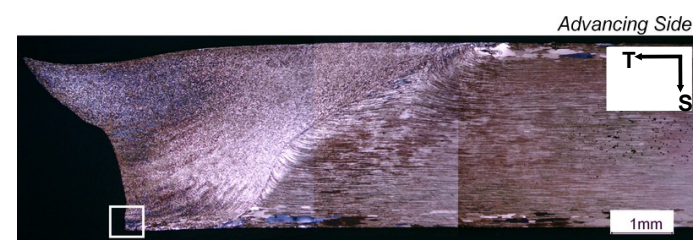

(c)

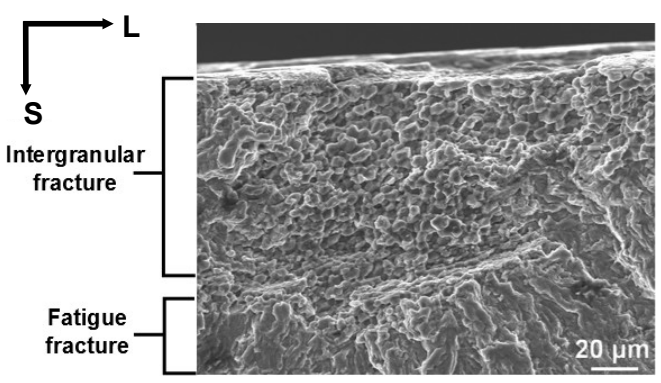

(b)

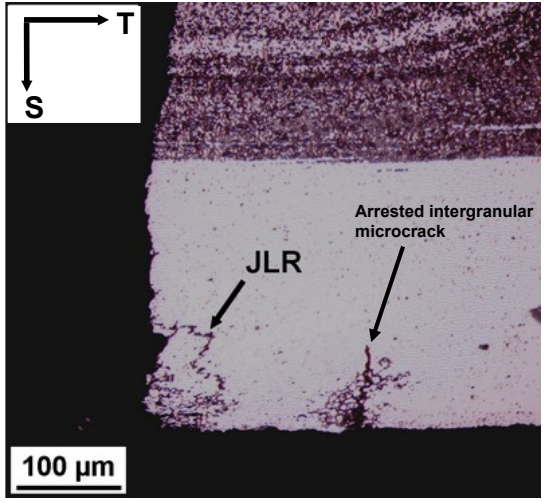

(d)

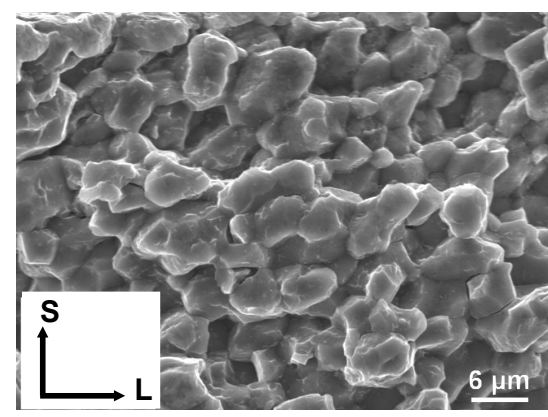

Figure 10: GAP $0.3 \mathrm{~mm}$ welds after failure (a),(b) LOM of a cross-section passing through the crack initiation region (fatigue zone is normal to the loading direction) (c) SEM fractography of the initiation site showing the intergranular fracture suface and the fatigue propagation region. (d) zoom on the intergranular fracture zone

\section{Conclusions}

The fatigue lifetime of latest generation Al-Cu-Li alloy (AA2198-T8 3.1 mm in thickness) FSW-welds has been assessed experimentally using smooth cross-weld tensile fatigue specimens $(R=0.1)$ for the following sound or defect- 
(a)

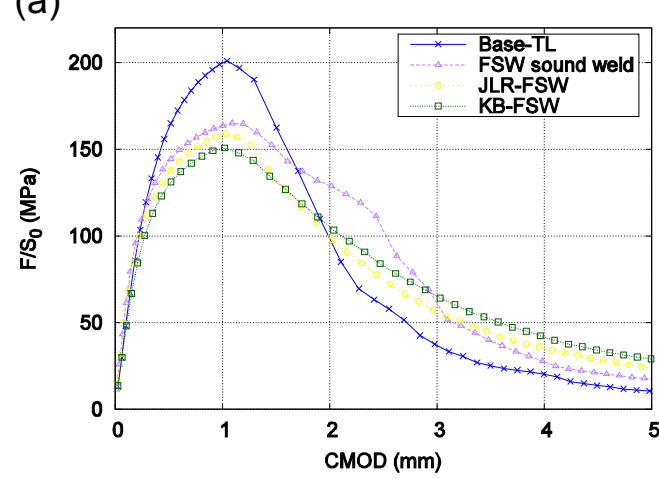

(c)

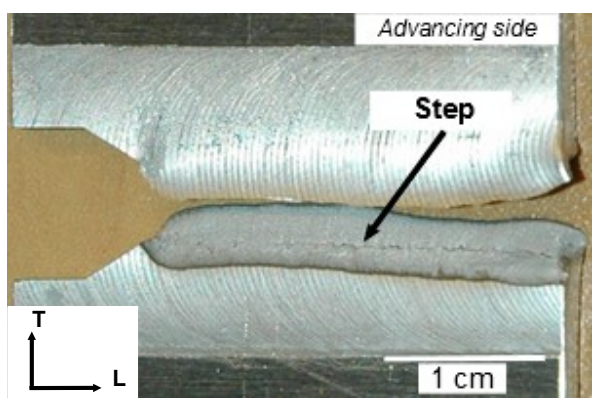

(b)

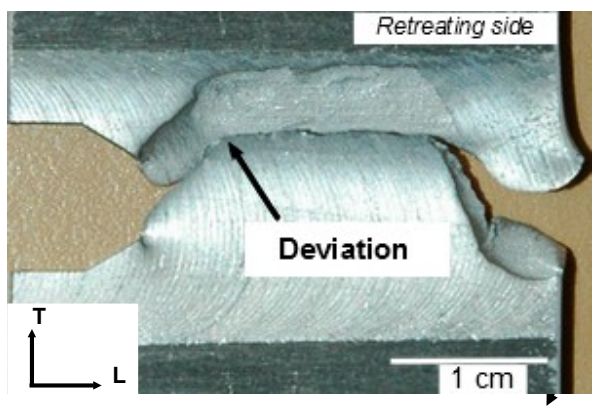

(d)

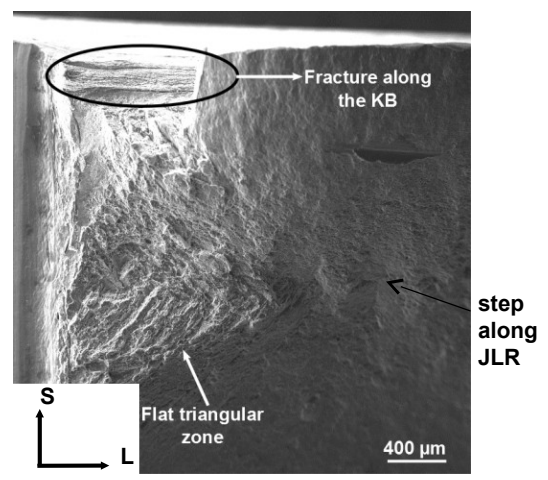

Figure 11: Kahn tear test results a) nominal stress versus CMOD curves for base material (T), sound, JLR-bearing and KB-bearing welds b) macroscopic crack deviation for sound weld c) step on the slanted fracture surface, caused by crossing the JLR c) fracture surface showing KB opening as ductile crack initiation

bearing materials:

- 1. base material,

- 2. sound weld (welded in one sheet),

- 3. welds containing Joint Line Remnant (JLR),

- 4. welds containing Kissing Bond (KB) with weld root polish,

- 5. welds containing KB with un-ground weld root,

- 6. welds with an initial $0.3 \mathrm{~mm}$ gap with un-ground weld root,

- 7. welds with an initial $0.7 \mathrm{~mm}$ gap with un-ground weld root. 
For the aimed lifetime of $10^{5}$ cycles the weld undergoes generalized plastic deformation which is supposed to redistribute and lower residual stresses [27], except for GAP welds.

At $10^{5}$ cycles base material and sound welds results in fatigue strength are similar $(290 \mathrm{MPa})$. A reduction by about $7 \%$ in fatigue strength is seen between sound welds and JLR bearing welds. There is no influence of JLR on crack initiation location. KB welds with ground root surface show a reduction in fatigue strength by $17 \%$ compared to sound welds. The opened $\mathrm{KB}$ is the crack initiation site for a maximum stress higher than $260 \mathrm{MPa}$, which is consistent with the results of an in situ monotonic tensile test [9]. A reduction of numbers of cycles to fatigue crack initiation is seen. However, this reduction also occurs for initiation outside the weld nugget that is likely to be attributed to the change in welding conditions (shorter pin and associated changes in material stirring) affecting the entire joint.

$\mathrm{KB}$ welds with unground weld root show a fatigue strength at $10^{5}$ cycles lifetime slightly lower than that of sound welds $(-7 \%)$ but surprisingly a higher fatigue lifetime than KB welds with ground weld root. The crack initiation site is independent of stress range in that case. This highlights that KB opening during the first load cycle is a function of $\mathrm{KB}$ orientation with respect to the loading direction as the KB close to the surface is strongly tilted with respect to the loading direction and thus not favourably oriented to initiate a crack. This tilted part does not systematically open during the first load cycle.

Using detailed fractographic information considering the opened KB as initial crack. The fatigue lifetime is clearly a function of the initial stress intensity factor range $\Delta \mathrm{K}$. A $\Delta \mathrm{K}$ threshold between $1.0-1.5 M P a \sqrt{m}$ has been evidenced. Two interrupted fatigue tests on $\mathrm{KB}$ welds with ground root surface confirm the reduction in number of cycles for crack initiation induced by opening of the KB.

For welds with and initial $0.3 \mathrm{~mm}$ GAP a reduction in fatigue strength by $28 \%$ is seen. For $10^{5}$ cycles to fracture the fatigue crack initiation location is an intergranular weld root crack created for loading above the yield stress of the nugget, that cannot be detected by tensile testing [9]. A reduction in number of cycles for fatigue crack initiation is seen. However, even in cases where the crack initiates from the TMAZ, a reduction in fatigue lifetime is found. This could be due to an influence of the missing surface grinding. Another reason could be that the entire welding process may have changed due to the initial gap, resulting in different properties and residual stresses 
T. Le Jolu et al., International journal of fatigue, 70 (2015) 463-472

of the TMAZ and HAZ. For welds with an initial $0.7 \mathrm{~mm}$ GAP the strongest reduction in fatigue lifetime is seen. Fracture occurs always from intergranular cracks.

The final fracture resistance of the welds, except forGAP welds, was assessed with Kahn specimens containing a notch in the weld centre. A fracture resistance ranking similar to the fatigue results is found.

\section{Acknowledgements}

This work was partly funded by the French National Foundation for Aircraft and Space (FNRAE) under the "MASAE" grant. Andre Pineau, Michel Suery and Sophie Gourdet are thanked for technical discussions.

\section{References}

[1] P. L. Threadgill, A. J. Leonard, H. R. Shercliff, P. J. Withers, Friction stir welding of aluminium alloys, International Materials Reviews 54 (2) (2009) 49-93.

[2] T. Warner, Recently-developed aluminium solutions for aerospace applications, Materials Science Forum 519-521 (2006) 1271-1278.

[3] J. Q. Chen, Y. Madi, T. F. Morgeneyer, J. Besson, Plastic flow and ductile rupture of a $2198 \mathrm{Al}-\mathrm{Cu}-\mathrm{Li}$ aluminum alloy, Computational Materials Science 50 (4) (2011) 1365-1371.

[4] P. S. De, R. S. Mishra, Friction stir welding of precipitation strengthened aluminium alloys: scope and challenges, Science and Technology of Welding and Joining 16 (4) (2011) 343-347.

[5] B. Decreus, A. Deschamps, F. D. Geuser, P. Donnadieu, C. Sigli, M. Weyland, The influence of $\mathrm{Cu} / \mathrm{Li}$ ratio on precipitation in $\mathrm{Al}-\mathrm{Cu}-$ Li-x alloys, Acta Materialia 61 (6) (2013) 2207 - 2218.

[6] Y. E. Ma, Z. Zhao, B. Liu, W. Li, Mechanical properties and fatigue crack growth rates in friction welded nugget of 2198-T8 Al-Li alloy joints, Material Science and Engineering A 569 (2013) 41-47.

[7] P. Cavaliere, A. De Santis, F. Panella, A. Squillace, Effect of anisotropy on fatigue properties of $2198 \mathrm{Al}-\mathrm{Li}$ plates joined by friction stir welding, Engineering Failure Analysis 16 (6) (2009) 1856-1865.

[8] T. Le Jolu, T. F. Morgeneyer, A. F. Gourgues, Effect of joint line remnant on fatigue lifetime of friction stir welded AlCuLi alloy, Science and Technology of Welding and Joining 15 (8) (2010) 695-699. 
T. Le Jolu et al., International journal of fatigue, 70 (2015) 463-472

[9] T. Le Jolu, T. F. Morgeneyer, A. Denquin, M. Sennour, A. Laurent, J. Besson, A.-F. Gourgues-Lorenzon, Microstructural characterization of internal welding defects and their effect on the plastic behavior of FSW joints of AA2198 Al-Cu-Li alloy, Metallurgical and Materials Transactions A (2014) under review.

[10] N. D. Alexopoulos, E. Migklis, A. Stylianos, D. P. Myriounis, Fatigue behavior of the aeronautical Al-Li (2198) aluminum alloy under constant amplitude loading, International Journal of Fatigue 56 (2013) 95-105.

[11] Y. S. Sato, F. Yamashita, Y. Sugiura, S. H. C. Park, H. Kokawa, FIBassisted TEM study of an oxide array in the root of a friction stir welded aluminium alloy, Scripta Materialia 50 (3) (2004) 365-369.

[12] S. Di, X. Yang, D. Fang, G. Luan, The influence of zigzag-curve defect on the fatigue properties of friction stir welds in 7075-T6 Al alloy, Materials Chemistry and Physics 104 (2-3) (2007) 244-248.

[13] H. B. Chen, K. Yan, T. Lin, S. B. Chen, C. Y. Jiang, Y. Zhao, The investigation of typical welding defects for 5456 aluminum alloy friction stir welds, Materials Science and Engineering A 433 (1-2) (2006) 64-69.

[14] Y. Uematsu, K. Tokaji, H. Shibata, Y. Tozaki, T. Ohmune, Fatigue behaviour of friction stir welds without neither welding flash nor flaw in several aluminium alloys, International Journal of Fatigue 31 (10) (2009) 1443-1453.

[15] L. Cui, X. Yang, G. Zhou, X. Xu, Z. Shen, Characteristics of defects and tensile behaviors on friction stir welded AA6061-T4 T-joints, Materials Science and Engineering A 543 (2012) 58-68.

[16] T. L. Dickerson, J. Przydatek, Fatigue of friction stir welds in aluminium alloys that contain root flaws, International Journal of Fatigue 25 (12) (2003) 1399-1409.

[17] A. J. Leonard, S. A. Lockyer, Flaws in friction stir welds, in: 4th International Symposium on Friction Stir Welding, Park City, USA, 2003.

[18] T. Vugrin, M. Schmucker, G. Staniek, Root flaws of friction stir welds an electron microscopy study, in: Symposium on Friction Stir Welding and Processing III, San Francisco, USA, 2005, pp. 277-284.

[19] S. Di, X. Yang, G. Luan, B. Jian, Comparative study on fatigue properties between AA2024-T4 friction stir welds and base materials, Materials Science and Engineering A 435-436 (2006) 389-395.

[20] C. Zhou, X. Yang, G. Luan, Effect of root flaws on the fatigue property of friction stir welds in 2024-T3 aluminum alloys, Materials Science and Engineering A 418 (1-2) (2006) 155-160. 
T. Le Jolu et al., International journal of fatigue, 70 (2015) 463-472

[21] B. Li, Y. Shen, W. Hu, The study on defects in aluminum 2219-T6 thick butt friction stir welds with the application of multiple non-destructive testing methods, Materials and Design 32 (4) (2011) 2073-2084.

[22] Y. S. Sato, H. Takauchi, S. H. C. Park, H. Kokawa, Characteristics of the kissing-bond in friction stir welded Al alloy 1050, Materials Science and Engineering A 405 (1-2) (2005) 333-338.

[23] F. Palm, H. Steiger, U. Hennebohle, The origin of particle (oxide) traces in friction stir welds, in: 4th International Symposium on Friction Stir Welding, Park City, USA, 2004.

[24] C. Zhou, X. Q. Yang, G. H. Luan, Effect of oxide array on the fatigue property of friction stir welds, Scripta Materialia 54 (8) (2006) 15151520.

[25] P. Wanjara, B. Monsarrat, S. Larose, Gap tolerance allowance and robotic operational window for friction stir butt welding of AA6061, Journal of Materials Processing Technology 213 (4) (2013) 631-640.

[26] K. Inada, H. Fujii, Y. S. Ji, Y. F. Sun, Y. Morisada, Effect of gap on FSW joint formation and development of friction powder processing, Science and Technology of Welding and Joining 15 (2010) 131-136.

[27] L. Fratini, G. Macaluso, S. Pasta, Residual stresses and FCP prediction in FSW through a continuous FE model, Journal of Materials Processing Technology 209 (15-16) (2009) 5465-5474.

[28] H. Lemmen, R. Alderliesten, R. Benedictus, Evaluating the fatigue initiation location in friction stir welded AA2024-T3 joints, International Journal of Fatigue 33 (2011) 466-476.

[29] Y. E. Ma, P. Staron, T. Fischer, P. E. Irving, Size effects on residual stress and fatigue crack growth in friction stir welded 2195-T8 aluminium - part I: Experiments, International Journal of Fatigue 33 (11) (2011) 1417-1425.

[30] G. Pouget, A. P. Reynolds, Residual stress and microstructure effects on fatigue crack growth in AA2050 friction stir welds, International Journal of Fatigue 30 (3) (2008) 463-472.

[31] H. Tada, P. C. Paris, G. R. Irwin, The stress analysis of cracks handbook, Del Research corporation, Hellertown, USA, 1973.

[32] S. Richard, Fissuration par fatigue d'alliages d'aluminium au lithium de troisieme generation, These de doctorat, Ecole Nationale Superieure de Mecanique et d'Aerotechnique, Poitiers (2011).

[33] S. Suresh, R. O. Ritchie, Propagation of short fatigue cracks, International Metals Reviews 29 (1) (1984) 445-475. 
T. Le Jolu et al., International journal of fatigue, 70 (2015) 463-472

[34] Y. E. Ma, P. Irving, Residual stress effects and fatigue behavior of friction-stir-welded 2198-T8 Al-Li alloy joints, Journal of Aircraft 48 (4) (2011) 1238-1244.

[35] D. Dumont, A. Deschamps, Y. Brechet, On the relationship between microstructure, strength and toughness in AA7050 aluminum alloy, Materials Science and Engineering A 356 (1-2) (2003) 326-336.

[36] T. Morgeneyer, J. Besson, Flat to slant ductile fracture transition: Tomography examination and simulations using shear-controlled void nucleation, Scripta Materialia 65 (2011) 1002-1005. 